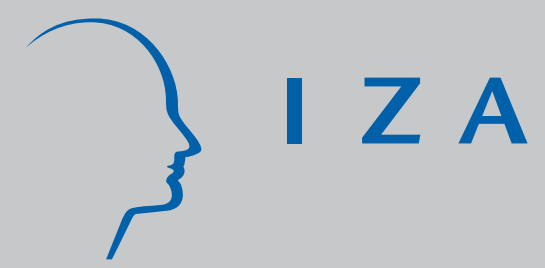

IZA DP No. 8109

Crime and Self-Control Revisited: Disentangling the Effect of Self-Control on Risk and Social Preferences

Tim Friehe

Hannah Schildberg-Hörisch

April 2014 


\title{
Crime and Self-Control Revisited: Disentangling the Effect of Self-Control on Risk and Social Preferences
}

\author{
Tim Friehe \\ CASTLE, University of Bonn \\ and CESifo \\ Hannah Schildberg-Hörisch \\ University of Bonn \\ and IZA
}

Discussion Paper No. 8109

April 2014

IZA

P.O. Box 7240

53072 Bonn

Germany

Phone: +49-228-3894-0

Fax: +49-228-3894-180

E-mail: iza@iza.org

\begin{abstract}
Any opinions expressed here are those of the author(s) and not those of IZA. Research published in this series may include views on policy, but the institute itself takes no institutional policy positions. The IZA research network is committed to the IZA Guiding Principles of Research Integrity.

The Institute for the Study of Labor (IZA) in Bonn is a local and virtual international research center and a place of communication between science, politics and business. IZA is an independent nonprofit organization supported by Deutsche Post Foundation. The center is associated with the University of Bonn and offers a stimulating research environment through its international network, workshops and conferences, data service, project support, research visits and doctoral program. IZA engages in (i) original and internationally competitive research in all fields of labor economics, (ii) development of policy concepts, and (iii) dissemination of research results and concepts to the interested public.
\end{abstract}

IZA Discussion Papers often represent preliminary work and are circulated to encourage discussion. Citation of such a paper should account for its provisional character. A revised version may be available directly from the author. 


\section{ABSTRACT}

\section{Crime and Self-Control Revisited: Disentangling the Effect of Self-Control on Risk and Social Preferences}

In economic models, risk and social preferences are major determinants of criminal behavior. In criminology, low self-control is considered a fundamental cause of crime. Relating the arguments from both disciplines, this paper studies the relationship between self-control and both risk and social preferences. To exogenously vary the level of self-control, we use a wellestablished experimental manipulation. We find that low self-control causes less risk-averse behavior. The effect of self-control on social preferences is not significant. In sum, our findings support the proposition that low self-control is a facilitator of crime. While our study is motivated by the literature on the determinants of criminal behavior, it has important implications for dual-system models and documents endogeneity of economic preferences.

JEL Classification: K42, H23, C91

Keywords: criminal behavior, risk preferences, social preferences, ego-depletion, dual-system models, experiment, endogeneity of economic preferences

Corresponding author:

Hannah Schildberg-Hörisch

Department of Economics

University of Bonn

Adenauerallee 24-42

53113 Bonn

Germany

E-mail: schildberg-hoerisch@uni-bonn.de 


\section{Motivation}

Crime is a social phenomenon of great importance, adversely affecting society as a whole and the countless individuals who are victimized each day (see, e.g., Anderson 1999). One of the most influential theories regarding its causes is the General Theory of Crime. It argues that low self-control "is the primary individual characteristic causing criminal behavior" (Gottfredson and Hirschi 1990: 111). The central tenet is that individuals with low selfcontrol are particularly vulnerable to temptations because they fail to take full account of the negative consequences of their acts. A criminal act has both an antisocial aspect since it imposes harm on the victims and a risk aspect because there is some chance of detection and subsequent sanctioning. The General Theory of Crime posits that individuals with low self-control are more likely to engage in criminal behavior since they are both more risktaking and more insensitive to others.

Similarly, risk and social preferences are crucial in economic models of criminal behavior. The seminal paper by Becker (1968) was the first to address the link between risk preferences and criminal behavior. Studies on the relationship between criminal behavior and social preferences are more recent and their count keeps growing. Falk and Fischbacher (2002), Schildberg-Hörisch and Strassmair (2012), Harbaugh et al. (2013), and Khadjavi (2014) mimic criminal behavior in laboratory experiments and use take games to elicit (anti)social preferences. Birkeland et al. (forthcoming) and Chmura et al. (2013) elicit social preferences of prisoners and find that they do not differ significantly from those of populations not incarcerated. ${ }^{1}$

This paper studies how self-control ability relates to risk and social preferences, thereby linking the General Theory of Crime to the economic literature on criminal behavior. More precisely, we test whether low self-control induces less risk-averse and more antisocial behavior. We use a laboratory experiment to be able to exogenously vary the level of selfcontrol across treatments and, thus, to provide causal evidence on the link between selfcontrol and both risk and social preferences.

\footnotetext{
${ }^{1} \mathrm{~A}$ related literature deals with the effect of income inequality on crime, see, for example, Fleisher (1966), Fajnzylber et al. (2002), or Chintrakarn and Herzer (2012).
} 
We use a $2 \times 2$ between-subject design. In the first stage, subjects participate in a version of a so-called ego-depletion task that induces either high or low self-control capabilities. In the second stage, we elicit subjects' risk or social preferences. In social psychology, egodepletion tasks are a standard tool to manipulate an individual's level of self-control. They are based on the intuition that self-control can be likened to a muscle that it is fatigued by prior use (e.g., Muraven and Baumeister 2000). The exertion of self-control in one activity is assumed to consume mental self-control resources, thereby diminishing self-control ability in subsequent activities (Muraven forthcoming). ${ }^{2}$ Once put in a state of low self-control (socalled ego-depletion) in the low self-control treatments, subjects are temporarily less able to exert self-control in the decision problems that elicit risk or social preferences. ${ }^{3}$

We find that individuals with lower self-control capability behave significantly less riskaverse. This effect is mainly driven by the behavior of male subjects. The effect of selfcontrol on social preferences is not significant.

In sum, our findings support the proposition of the General Theory of Crime that low selfcontrol is a facilitator of crime. Our study complements empirical studies that suggest a link between crime and low self-control, but struggle to establish causality because they lack an exogenous manipulation of self-control (see the meta-analyses by Engel 2012 and Pratt and Cullen 2000).

Our research also adds to the ongoing discussion about the role of rational choice in theories about crime. For example, De Haan and Vos (2003) argue for the case of street robbery that the rational-choice perspective does not add much, because it misses essential aspects such as impulsiveness and moral ambiguity. In our paper, we investigate how subjects with low self-control, i.e., subjects acting more impulsively, decide and compare their choices to the behavior of subjects with higher self-control. Our results suggest that individuals who act more impulsively are indeed less likely to be deterred by probabilistic sanctioning.

\footnotetext{
${ }^{2}$ Self-control resources are required when situations and tasks involve conflict and a need to suppress natural tendencies, such as resisting a temptation, thought control, control of affect, or persisting on complex cognitive tasks (Kahneman 2011: 42).

${ }^{3}$ Current psychological and criminological research suggests that the level of self-control at a given point in time depends both on situational aspects and a stable personality trait self-control (e.g., Muraven et al. 2006, Wikström and Treiber 2007). In our study, we manipulate the level of situational self-control ability and collect information about the level of trait self-control in a post-experimental questionnaire.
} 
Moreover, our paper points at a potential mechanism underlying empirical findings on crime and factors which, surprisingly, have predictive power for crime. Examples are the relationship between crime and hot weather (Jacob et al. 2007) or the relationship between family or hooligan violence and the unexpectedly bad performance of sports teams (Card and Dahl 2011, Priks 2010). If hot weather or an unexpected loss of the own team consume self-control resources, lower self-control ability in subsequent situations might increase an individual's inclination to engage in criminal behavior.

Our key research question whether low self-control causes less risk-averse and more antisocial behavior has also important implications beyond the analysis of causes of criminal behavior. First, our paper adds to the literature on dual-system models, such as Fudenberg and Levine (2006, 2011, 2012), Kahneman (2003), and Loewenstein and O'Donoghue (2007). ${ }^{4}$ According to dual-system models, decision-making is governed by the interaction of an instinctive affective system and a controlled deliberative system. Exerting self-control is required for implementing deliberative processes and overriding affective processes. Our low self-control treatment diminishes mental resources left for further self-control and thereby enhances the influence of the affective system on behavior. In the light of dualsystem models, our result that individuals with lower self-control ability are less risk-averse contrasts with the deliberative system ("long-run self") being less risk-averse than the affective system ("short-run self") in the dual-system model of Fudenberg and Levine (2006, 2011).

Second, by documenting systematic variations in risk preferences due to changes in selfcontrol capabilities, we contribute to the discussion on the endogeneity of preferences. Traditionally, economists treat preferences as exogenously given and explain changes in behavior by changes in beliefs or constraints that people face rather than by changes in preferences. This view is increasingly challenged. For example, Fehr and Hoff (2011) provide a general discussion of the influence of society on preferences. Moreover, there is an emerging literature on the effect of emotions on risk preferences (Conte et al. 2013, Guisi et al. 2013, Nguyen and Noussair 2013).

\footnotetext{
${ }^{4}$ For a recent, more general discussion of the dual-system approach, see Evans (2008), Rustichini (2008), or Kahneman (2011).
} 
Our paper is most closely related to Muraven et al. (2006) who compare the level of subjects' cheating (as a form of deviant behavior) in a low self-control condition with that of subjects in a high self-control condition. They find that subjects with low self-control cheat more. In contrast to our paper, cheating was inconsequential for others (i.e., not antisocial) and not incentivized. Moreover, our study also investigates the effect of low self-control on risk attitudes since, in real-life circumstances, crime is subject to probabilistic sanctioning. ${ }^{5}$

The remainder of our paper is structured as follows. In Section 2, we describe the experiment design and procedures. Section 3 spells out the hypotheses, before Section 4 presents results. Section 5 embeds our results in those obtained in the related literature. Section 6 concludes.

\section{Experiment design, treatments, and procedures}

We first describe the experiment design and the four treatments. Next, we provide details on the implementation of the experiment. Appendix B contains a translated example of the instructions that subjects received in the beginning of the experiment.

\subsection{Experiment design and treatments}

To investigate how low self-control influences criminal behavior in situations with probabilistic law enforcement, we separately analyze the effect of self-control on risk and social preferences, i.e., the two components that are key to the decision of whether or not to engage in criminal behavior. For a sound understanding of the mechanisms underlying the relationship between self-control and criminal behavior, a separate analysis of the effects of self-control on risk and social preferences is crucial since the two effects could potentially offset each other. For example, if subjects with low self-control behave in a more selfish and a more risk-averse manner, the first effect will increase and the second effect will decrease the attractiveness of criminal behavior, which may result in unchanged behavior.

\footnotetext{
${ }^{5}$ DeBono et al. (2011) provide a study on cheating that is closely related to Muraven et al. (2006), but add the comparison of an anonymous condition with one in which subjects could, in principle, be identified. As another example of norm-deviant behavior, they report evidence that subjects with low self-control are less likely to show polite behavior.
} 
Our central research question is whether subjects with low self-control capability behave less risk-averse and more antisocial than subjects with higher self-control capability. We use a $2 \times 2$ design to address this question. The first treatment dimension distinguishes subjects who participate in the ego-depletion task that induces low self-control capability (LSC treatment) from subjects who take part in the ego-depletion task that results in higher selfcontrol capability (HSC treatment). The second treatment dimension is whether a subjects' risk or social preferences are elicited first. For each subject, we measure both risk and social preferences, but the order of decisions differs across treatments. The second decision was announced only after subjects had taken their first decision. Table 1 summarizes the four treatments.

Table 1: Treatments

\begin{tabular}{|c|c|c|c|c|}
\hline & Ego-depletion task & First decision elicits & $\begin{array}{c}\text { Second decision } \\
\text { elicits }\end{array}$ & $N$ \\
\hline Treatment 1 & high self-control & risk preferences & social preferences & 43 \\
\hline Treatment 2 & high self-control & social preferences & risk preferences & 43 \\
\hline Treatment 3 & low self-control & risk preferences & social preferences & 47 \\
\hline Treatment 4 & low self-control & social preferences & risk preferences & 47 \\
\hline
\end{tabular}

We describe the different stages of our experiment in more detail below.

Ego-depletion task:

To induce variations in situation-specific self-control, we use the crossing-out-letters task, one of the best established and most frequently used ego-depletion tasks (see the metaanalysis by Hagger et al. 2010 and Baumeister et al. 1998). This non-interactive, paper-andpencil task had two parts lasting seven minutes each. In both parts, participants got a text with six paragraphs. Each paragraph had six lines of text. The content of the text (about the pros and cons of different kinds of statistics software) was chosen to be relatively boring, and, thus, not distracting. 
For the first part of the task, subjects in both the LSC and the HSC treatment were instructed to cross out and count each instance of the letter " $\mathrm{e}$ ", paragraph after paragraph. This habituated all subjects to crossing out each instance of the letter " $\mathrm{e}$ ". In the second part of the task, subjects in the LSC treatment received the new instruction to cross out and count each letter " $\mathrm{e}$ " unless another vowel immediately followed the letter " $\mathrm{e}$ " or unless another vowel was at a distance of exactly two letters from the letter " $e$ " (in either direction). Looking at _ _ $e_{-}$, the letter " $e$ " should not be crossed out when there was a vowel on position 1, 3, or 4. Participants in the HSC treatment were provided with the same text, but asked to continue crossing out and counting each letter " $\mathrm{e}$ " (i.e., maintain the habituated behavior in part 2 of the task). These instructions ensured that only subjects in the LSC treatment had to consume self-control resources to inhibit the habituated urge to cross out each letter " $e$ " in part 2 of the task.

We refrained from incentivizing performance in the ego-depletion task because there is evidence that monetary incentives can mitigate depletion effects (Muraven and Slessareva 2003). We repeatedly emphasized the importance of doing the task right and collected the task sheets for later control. Moreover, subjects knew that they would receive private feedback about their performance in the crossing-out-letters task on the computer screen at the end of the experiment.

\section{Risk preferences:}

In order to elicit risk preferences, we use the basic setup of Gneezy and Potters (1997) and the subsequent literature surveyed in Charness and Gneezy (2012). Each subject receives 20 points and decides how many points y to invest in a risky option and how many to keep. The invested amount y yields a dividend of $2.5 \mathrm{y}$ with probability $1 / 2$ and is lost with probability $1 / 2$, where $y \in\{0,1,2, \ldots, 20\}$. The money not invested, $20-y$, is kept by the subject. The resulting payoffs are $20-y+2.5 y$ with probability $1 / 2$ and $20-y$ with probability $1 / 2$. Given our parameters, risk-neutral and risk-seeking individuals invest all 20 points, while different investment levels below 20 reflect different degrees of risk aversion. At the end of the experiment, 4 points were converted into 1 Euro. 
Social preferences:

We use a take game version of the dictator game to elicit (anti)social preferences. Two subjects are matched randomly and anonymously. Each participant obtains an initial endowment of 20 points. One of the two subjects decides how many points $x$ to take from the other passive subject, where $x \in\{0,1,2, \ldots, 20\} .{ }^{6}$ When taking $x$ points from the other subject, the taking subject obtains $20+x / 4$ and the other subject receives $20-x$. This setting clearly suggests that taking points is antisocial since it is characterized by an initially equal distribution of endowments and a drastic inefficiency of taking. In order to disentangle the effect of self-control on social and risk preferences, we do not add a probabilistic sanctioning scheme to the take game. We share these features - inefficiency of taking from others and absence of law enforcement - with Falk and Fischbacher's (2002) setup of "crime" in the lab.

\subsection{Experiment procedures}

Subjects received written instructions that described the ego-depletion task in detail and their first decision in general terms. In order to prevent that subjects could plan their exact decision before completing the ego-depletion task, we represented the level of endowment, the inefficiency parameter in the take game and the dividend in the winning state of nature of the risky investment as general variables. In view of the evidence that many people struggle with the concept of probabilities, we included the probability of $50 \%$ in the written instructions. The second decision was only announced after subjects had made their first decision to keep the first decision as clean as possible.

In each session, we elicited social preferences in the first decision and risk preferences in the second decision for half of the subjects. The other half of subjects first made the decision that elicits risk preferences followed by the decision that elicits social preferences. In the take game, the active subject was randomly matched with another subject taking the risky investment decision at that time. After participating in the ego-depletion task and making the two decisions, subjects filled out a questionnaire eliciting data on their trait self-control, age, sex, and subject of studies, among others.

\footnotetext{
${ }^{6}$ The wording of the instructions was "As participant B, you choose an integer transfer amount that you would like to take from participant A's endowment."
} 
The experiment was run in August and October 2013 at the experimental laboratory of the University of Bonn, Germany (BonnEconLab). We used the experimental software z-Tree (Fischbacher 2007) and the recruitment software ORSEE (Greiner 2003). In total, 180 students of various fields of study participated. Subjects were randomly assigned to sessions. Sessions were framed neutrally and lasted about 60 minutes. Subjects did not receive a show-up fee and earned 13.04 Euro on average.

\section{Hypotheses}

We derive our hypotheses from the General Theory of Crime (Gottfredson and Hirschi 1990), which posits that individuals with low self-control are prone to criminal behavior since they are less risk-averse and more insensitive towards others.

H1: Lower self-control causes less risk-averse behavior.

H2: Lower self-control causes more antisocial behavior.

Dual-system models offer an alternative source for deriving hypotheses. According to dualsystem models, subjects' behavior in the low self-control treatment should be more affectbased. Fudenberg and Levine $(2006,2011)$ present a dual-system model in which the affective system is more risk-averse than the deliberative one, which contrasts with Hypothesis $\mathrm{H} 1$.

Hypothesis $\mathrm{H} 2$ implies that selfish behavior is pushed by the affective system and inhibited by the deliberative system. Hypothesis H2 is supported by Moore and Loewenstein (2004) and Rachlin (2002), for example, while Haidt (2001) considers moral decisions to be automatic.

When testing Hypotheses $\mathrm{H} 1$ and $\mathrm{H} 2$, we focus on the effect of situation-specific self-control on risk and social preferences since our experiment design allows for an exogenous manipulation of situation-specific self-control. Additionally, we test $\mathrm{H} 1$ and $\mathrm{H} 2$ using information on the level of trait self-control based on the standard Grasmick scale (Grasmick et al. 1993) that we have elicited in the post-experimental questionnaire. 


\section{Results}

We will first discuss results on the manipulation of self-control via the ego-depletion task. We then turn to the causal effect of self-control on risk preferences, before we present results on the relationship between self-control and social preferences.

For the analysis to come, we use the first decision of our subjects. First decisions are cleanest, since they cannot be affected by previous decision behavior. For example, the second decision could be affected by (expected) earned income in the first decision or consistency considerations. Furthermore, depletion effects will fade out over time and there is no evidence on how quickly self-control resources replenish. Using data from first decisions ensures that differences in self-control across treatments are still present. In our data, we indeed find that subjects behave significantly different in first and second decisions. Specifically, we find order effects for risk preferences in LSC (Mann-Whitney-U test (MWU), $\mathrm{p}=.02)^{7}$ and social preferences in HSC (MWU, $p=.03$ ).

\subsection{Ego-depletion task}

The first part of the crossing-out-letters task was identical in treatments HSC and LSC. Thus, we can compare the average performance of subjects in HSC and LSC in the first part to check for any systematic differences in group composition across treatments (e.g., differences in ability in crossing-out letters, motivation, or initial concentration). Reassuringly, the number of paragraphs worked on with high precision was not significantly different in LSC and HSC (MWU, $p=0.47$ ), where high precision means that the number of counted letters " $e$ " is within a range of $+/-5$ of the true number that varied between 64 and 91 across paragraphs. The mean number of paragraphs worked on with high precision was 2.92 (SD 1.22) in HSC and 3.05 (SD 1.27) in LSC. Turning to the number of completed paragraphs in the second part of the task that differed across treatments, we find that the maximum (minimum) number of completed paragraphs in HSC was 6 (2), while the maximum (minimum) number of completed paragraph in LSC was 3 (1). After the experiment, subjects had to indicate on a sliding scale ranging from 'not at all' to 'extremely' to which extent they had to concentrate to perform the two parts of the crossing-out-letters task. We find that the second part required significantly more concentration in LSC than in HSC (MWU, $p<.01$ ) and

\footnotetext{
${ }^{7}$ Throughout the paper, we report two-sided p-values.
} 
that the difference in the concentration required for part 2 and part 1 was significantly higher for subjects in LSC (MWU, p<.01). As intended, treatment LSC was more demanding than treatment HSC.

In general, subjects worked on the crossing-out-letters task in a concentrated and ambitious manner. We are very confident that participation in treatment LSC resulted in subjects having less self-control resources available than their counterparts in treatment HSC. The results on effect sizes in the meta-analysis of Hagger et al. (2010) imply that the crossingout-letters task is an ego-depletion task that is especially successful in inducing low selfcontrol resources.

\subsection{Subjects with low self-control are less risk-averse}

Table 2 reports the mean investment in the risky option out of a total of 20 points for the full sample and according to gender. For the whole sample, we find that subjects in LSC behave less risk-averse. Subjects with low self-control invest $18 \%$ (or 1.7 points) more in the risky option than subjects with high self-control. This is a large effect: other studies using egodepletion manipulations often find only subtle effect sizes. ${ }^{8}$ Moreover, DeBono et al. (2011) argue that providing incentives for the decisions that follow the ego-depletion task is likely to weaken treatment differences (because depletion can be overcome if the situation is important enough).

Table 2: Mean level and standard deviation of investment in the risky option (whole sample and gender-specific)

\begin{tabular}{|l|c|c|c|c|c|c|}
\hline & $\begin{array}{c}\text { All } \\
\text { in HSC }\end{array}$ & $\begin{array}{c}\text { All } \\
\text { in LSC }\end{array}$ & $\begin{array}{c}\text { Male } \\
\text { in HSC }\end{array}$ & $\begin{array}{c}\text { Male } \\
\text { in LSC }\end{array}$ & $\begin{array}{c}\text { Female } \\
\text { in HSC }\end{array}$ & $\begin{array}{c}\text { Female } \\
\text { in LSC }\end{array}$ \\
\hline Mean level (SD) of & 8.98 & 10.64 & 9.81 & 13.83 & 8.18 & 8.66 \\
Investment & $(5.60)$ & $(5.57)$ & $(6.01)$ & $(5.47)$ & $(5.20)$ & $(4.72)$ \\
\hline$N$ & 43 & 47 & 21 & 18 & 22 & 29 \\
\hline
\end{tabular}

We additionally provide gender-specific results on risk preferences and the effect of selfcontrol on risk preferences to reflect the comprehensive evidence that risk preferences of

\footnotetext{
${ }^{8}$ See, for example, Achtziger et al. (2012) for a paper that uses a very similar crossing-out-letters task as we do.
} 
men and women differ (see Charness and Gneezy (2012) for a survey of results based on the risk preferences elicitation tool that we use and Croson and Gneezy (2009) for a general survey). Gender-specific results show that inducing low self-control has a strong effect on risk preferences of male subjects, while risk preferences of female subjects are hardly affected by differences in self-control. On average, male subjects invest 9.8 out of 20 points in the risky option in HSC, but 13.8 in LSC. For men, distributions of investments in the risky option differ significantly in HSC and LSC (MWU, $p=.06$ ). For women, the average investment difference in the risky option is only about 0.5 points and not significant (MWU, $p=.46$ ). ${ }^{9}$

Table 3 displays regression results on the effect of self-control on risk preferences based on a tobit model. The treatment effect is captured by the dummy variable Low self-control, which is equal to one if a subject participated in LSC and zero otherwise. The gender dummy Female is one for women and zero for men. In other words, our reference group is male subjects in the high self-control treatment. Moreover, we include a measure for the level of Trait self-control that is based on the Grasmick scale and results from responses to the postexperimental questionnaire.

Since there are substantially more female subjects in treatment LSC ( 29 female compared to 18 male subjects) and gender differences in risk-taking behavior are well documented, drawing conclusions on treatment comparisons based on non-parametric tests implicitly overweighs female risk-taking behavior in a state of low self-control. In contrast, in a regression analysis, we can easily control for both baseline and potential treatment-specific gender differences. Thus, regression analysis is a more appropriate method to isolate treatment differences that are due to differences in self-control from gender differences in behavior.

\footnotetext{
${ }^{9}$ In order to be transparent about our data and to provide a further illustration of gender-specific treatment effects, Figure 1 in Appendix A contains histograms of investments in the risky option that are arranged by selfcontrol and gender.
} 
Table 3: The effect of self-control on risk preferences

\begin{tabular}{l|ccc} 
& $(1)$ & $(2)$ & $(3)$ \\
\hline Low self-control & $2.383^{*}$ & $5.274^{* *}$ & $5.251^{* *}$ \\
& {$[1.366]$} & {$[2.422]$} & {$[2.420]$} \\
Female & $-4.060^{* * *}$ & -1.532 & -1.514 \\
& {$[1.444]$} & {$[1.993]$} & {$[2.020]$} \\
Female*Low self-control & & $-5.031^{*}$ & $-4.993^{*}$ \\
& & {$[2.907]$} & {$[2.916]$} \\
Trait self-control & & & 0.006 \\
& & & {$[0.059]$} \\
Constant & $11.243^{* * *}$ & $9.931^{* * *}$ & $9.924 * * *$ \\
& {$[1.366]$} & {$[1.580]$} & {$[1.595]$} \\
\hline Observations & 90 & 90 & 90 \\
Pseudo R-squared & 0.0196 & 0.0261 & 0.0261
\end{tabular}

Notes: Coefficient estimates from tobit regressions. The dependent variable is the level of investment in the risky option and in the range [0,20]. Female and Low self-control are dummy variables, whereas Trait selfcontrol is continuous. Robust standard errors in brackets. ${ }^{* * *} p<.01,{ }^{* *} p<.05,{ }^{*} p<.1$.

Column (1) in Table 3 documents a significant treatment effect for the sample as a whole: subjects in LSC invest significantly more in the risky option $(p<1)$, i.e., subjects with low selfcontrol behave less risk-averse. Column (2) shows that the overall treatment effect is due to a change in the behavior of male subjects: while low self-control induces men to behave less risk averse $(p<.05)$, women's behavior is nearly unchanged $(p=.88$ in an F-test for the joint significance of Low self-control and the interaction term Female* Low self-control). In Column (3), we add trait self-control as an additional explanatory variable. Trait self-control does not significantly predict risky investments. This is also true if trait self-control is the only explanatory variable in addition to the female dummy variable and if we allow for a genderspecific relation of trait self-control and risky investments (results not displayed). Engel (2012) reports that studies that use the Grasmick scale generally report a lower sensitivity of deviant behavior to changes in self-control than studies relying on other measures of selfcontrol. 
We summarize the findings of this section:

\section{Result 1a: Low situational self-control causes significantly less risk-averse behavior.}

\section{Result 1b: Low trait self-control is not a significant predictor of risk preferences.}

Next, we turn to Hypothesis $\mathrm{H} 2$ that addresses the effect of self-control on social preferences as measured in the take game.

\subsection{No significant effect of self-control on social preferences}

Our measure of social preferences is the number of points that subjects take from the endowment of another subject who initially possesses 20 points. Table 4 reports the average amount taken for the full sample and according to gender. In contrast to Hypothesis $\mathrm{H} 2$ that is based on the General Theory of Crime, we find that on average subjects take $12 \%$ (1.6 points) less in treatment LSC than in treatment HSC, i.e., subjects with low self-control tend to behave more prosocial.

Similar to the case of risk preferences, there is some (somewhat weaker) evidence for gender differences in social preferences in our data. Such differences are reported frequently, although the evidence is not as clear-cut for social preferences as it is for risk preferences (see, e.g., the survey of Croson and Gneezy 2009). ${ }^{10}$ The gender-specific results illustrate that the overall difference in social preferences arises due to the effect of selfcontrol on social preferences of female subjects. On average, women in LSC take 2 points less than in HSC. The distribution of the taken amount by women, however, is not significantly different for high and low self-control ( $M W U, p=.19)$. The average taken amount of men is nearly unchanged across treatments and there is no significant treatment difference (MWU, $\mathrm{p}=.96){ }^{11}$

\footnotetext{
${ }^{10}$ In an especially careful study of a dictator game, Eckel and Grossman (2008) conclude that women behave more prosocial than men. However, our take game is in the domain of antisocial as opposed to prosocial behavior and additionally characterized by inefficiency of transfers. Varying the price of giving in a dictator game, Andreoni and Vesterlund (2001) show that men care more about efficient outcomes, which, in our experiment, could decrease potential gender differences in social preferences. With respect to antisocial or deviant behavior, Dreber and Johannesson (2008) and Erat and Gneezy (2012) document that women are more averse to lying.

${ }^{11}$ Figure 2 in Appendix A contains histograms of the taken amount that are arranged by self-control and gender.
} 
Table 4: Mean level and standard deviation of taken amount

(whole sample and gender-specific)

\begin{tabular}{|l|c|c|c|c|c|c|}
\hline & $\begin{array}{c}\text { All } \\
\text { in HSC }\end{array}$ & $\begin{array}{c}\text { All } \\
\text { in LSC }\end{array}$ & $\begin{array}{c}\text { Male } \\
\text { in HSC }\end{array}$ & $\begin{array}{c}\text { Male } \\
\text { in LSC }\end{array}$ & $\begin{array}{c}\text { Female } \\
\text { in HSC }\end{array}$ & $\begin{array}{c}\text { Female } \\
\text { in LSC }\end{array}$ \\
\hline Mean level (SD) & 13.91 & 12.28 & 14.95 & 14.65 & 12.91 & 10.93 \\
of taken amount & $(7.02)$ & $(7.12)$ & $(7.3)$ & $(7.8)$ & $(6.75)$ & $(6.45)$ \\
\hline$N$ & 43 & 47 & 21 & 17 & 22 & 30 \\
\hline
\end{tabular}

We next turn to tobit regression results presented in Table 5. Neither situational self-control (column (1)-(3)) nor trait self-control (column (3)) is a significant predictor of social preferences. ${ }^{12}$ Despite the 2 points difference in the taken amount across treatments, the female-specific treatment effect is not significant either: a joint F-test on the coefficients of Low self-control and Female*Low self-control in column (2) yields $p=.21$. Both in treatment HSC and LSC, women take less than men. The overall gender difference in social preferences is marginally significant $(p<.1)$, see column (1).

\footnotetext{
${ }^{12}$ Also when allowing for a gender-specific effect of trait self-control on social preferences, trait self-control does not have predictive power.
} 
Table 5: The effect of self-control on social preferences

\begin{tabular}{l|ccc} 
& $(1)$ & $(2)$ & $(3)$ \\
\hline Low self-control & -2.687 & -0.534 & -0.454 \\
Female & {$[2.827]$} & {$[5.209]$} & {$[5.164]$} \\
& $-5.527^{*}$ & -3.725 & -3.586 \\
Female*Low self-control & {$[2.964]$} & {$[4.254]$} & {$[4.317]$} \\
& & -3.546 & -3.555 \\
Trait self-control & & {$[6.107]$} & {$[6.077]$} \\
& & & 0.104 \\
Constant & & & {$[0.166]$} \\
& $19.999 * * *$ & $19.022^{* * *}$ & $18.819 * * *$ \\
\hline Observations & {$[2.796]$} & {$[3.328]$} & {$[3.379]$} \\
Pseudo R-squared & 90 & 90 & 90 \\
\hline
\end{tabular}

Notes: Coefficient estimates from tobit regressions. The dependent variable is the number of points taken from another participant and in the range [0, 20]. Female and Low self-control are dummy variables, whereas Trait self-control is continuous. Robust standard errors in brackets. $* * * p<.01,{ }^{* *} p<.05,{ }^{*} p<.1$.

We summarize the findings of this section:

Result 2a: Low situational self-control does not have a significant impact on social preferences.

Result 2b: Low trait self-control is not a significant predictor of social preferences.

\section{Related literature and discussion of results}

In this section, we first compare our results to those of other studies that also use an egodepletion manipulation and study the effect of self-control on risk-related and prosocial behavior (both defined in a very broad sense). Besides ego-depletion, time pressure and cognitive load are two further mechanisms that have been used to study predictions of dualsystem models. In the dual-system paradigm, low self-control, high time pressure, and high cognitive load are often considered alternative tools to induce more automatic and affectbased decisions as opposed to more deliberative ones (e.g., Lobel and Loewenstein 2005). 
Therefore, we proceed by briefly discussing the literature on the effects of time pressure or cognitive load on risk preferences and social preferences.

Using an ego-depletion manipulation, Freeman and Muraven (2010) find that subjects with low self-control are less "risk"-averse. However, choices in their first experiment were not incentivized and subjects in both experiments decided under ambiguity instead of risk (i.e., without knowing the probabilities of the different states of the world). Unger and Stahlberg (2011) report that depleted subjects with low self-control make more risk-averse decisions. In their strongly framed investment experiment, subjects were asked to imagine that they were a manager making a decision on behalf of their firm. Consequently, subjects' decisions do not necessarily reflect only their own risk preferences. ${ }^{13}$ In contrast, our experiment is the first to use a standard tool applied by many economists for measuring risk preferences (the one introduced by Gneezy and Potters 1997) and documents that depleted subjects with low self-control behave less risk-averse.

A few papers use an ego-depletion manipulation to investigate the effect of low self-control on prosocial behavior, while our focus is on antisocial behavior. In an ultimatum game, Achtziger et al. (2012) find that depleted proposers make slightly lower offers than nondepleted proposers. ${ }^{14}$ Acceptance rates of depleted and non-depleted responders are not significantly different. It is difficult to compare our setting to that of Achtziger et al. (2012) because we have no similar strategic, interactive, or repeated game element. If anything, one could argue that our finding that social preferences are not significantly affected by selfcontrol has a similar spirit as responder behavior in Achtziger et al. (2012). Even more loosely related to our study, Xu et al. (2012) show that, in a dictator game, depleted subjects give away less money than non-depleted subjects to apologize for previously imposing negative externalities (loud noise) on other participants. DeWall et al. (2008) report data about the effects of low self-control on helping and find that depleted subjects are less willing to help. Gino et al. (2011) consider the link between ego-depletion and cheating the experimenter in a problem-solving task and document that more depleted subjects

\footnotetext{
${ }^{13}$ For example, Pahlke et al. (2012) provide evidence that individuals behave more risk averse in the gain domain if others are affected by their decision as well.

${ }^{14}$ Depleted proposers offer 2.68 Euro out of a total of 7 Euro to responders, whereas non-depleted proposers offer 2.84 Euro. Due to the large number of observations in their repeated game, this small difference is statistically significant.
} 
overstate their performance. In contrast to our take game, cheating has no efficiency implications and does not impose harm on another participant of the experiment.

We now turn to studies that use time pressure instead of ego-depletion to induce decisions steered by the affective system (based on the assumption that deliberative processes are more time-consuming than affective ones). Sutter et al. (2003) and Cappalletti et al. (2011) study ultimatum games and find that responders under time pressure are more likely to reject. These results suggest that, fairness considerations have a greater weight relative to monetary considerations under the affective system rather than the deliberative system. Additionally, Cappalletti et al. (2011) find that proposers offer more under time pressure. Proposer behavior is less straightforward to interpret, since proposers may also reason strategically.

Cognitive load is still another manipulation which consumes self-control resources. In contrast to ego-depletion which exhausts self-control resources before the decision of interest, cognitive load occupies self-control resources during the decision of interest. Schulz et al. (forthcoming), Hauge et al. (2009), and Cornelissen et al. (2011) use dictator games to study the effect of cognitive load on prosocial behavior. Hauge et al. (2009) and Cornelissen et al. (2011) do not find a significant treatment effect of cognitive load on prosocial behavior ${ }^{15}$, while in Schulz et al. (forthcoming) subjects with higher cognitive load behave more prosocial. In the domain of risky choices, Benjamin et al. (2012) report results of an experiment in which higher cognitive load induces more risk-averse behavior.

In sum, studies on the effect of low self-control (induced by ego-depletion, time pressure, or cognitive load) on risk preferences are scarce. In contrast, somewhat more evidence is available on the relation between self-control and prosocial behavior. However, these studies differ widely in which facet of prosocial behavior they measure and in how they manipulate self-control, which makes it somewhat hazardous to compare their results. Still it is fair to say that, so far, evidence on the effect of self-control on social preferences is inconclusive. Our study adds evidence on the absence of a significant effect of self-control on antisocial behavior.

\footnotetext{
${ }^{15}$ In their study of the ultimatum game, Cappalletti et al. (2011) also consider a cognitive load manipulation and do not find a significant treatment effect.
} 


\section{Conclusion}

Perpetrators are popularly considered to be impulsive with little ability to resist temptations posed by criminal opportunities. The influential General Theory of Crime proposes that low self-control ability is the most important cause of crime. It argues that individuals with low self-control behave in a less risk-averse and more antisocial manner. Our study exogenously manipulates the level of self-control in a laboratory experiment to explore the causal effect of self-control on risk and social preferences. We do not find a significant effect of selfcontrol on social preferences. As hypothesized in the General Theory of Crime, we find that subjects with low self-control resources are less risk-averse. It is noteworthy that this result contrasts with the dual-system model of Fudenberg and Levine (2006) that suggests that lower self-control induces more risk-averse behavior. Furthermore, the result that lower self-control causes less risk-averse behavior provides an example for endogenous risk preferences.

In sum, our results support the proposition of the General Theory of Crime that low selfcontrol is a facilitator of criminal behavior. Taking the gender-specificity of effects into account, our results imply that it is mainly men with low self-control who are more likely to engage in crime.

\section{Acknowledgements}

Financial support from SFB-TR 15 is gratefully acknowledged. We thank Majied Ammar Mahran and Geraldine Reichard for excellent assistance in programming and implementing the experiment. We are grateful for the helpful comments by Laszlo Goerke, Matthias Wibral, Jana Willrodt, and participants in research seminars at the University of Düsseldorf and the University of Trier. 


\section{References}

Achtziger, A., Alos-Ferrer, C., and A.K. Wagner, 2012. Social preferences and self-control. Mimeo.

Anderson, D.A., 1999. The aggregate burden of crime. Journal of Law and Economics 42, 611-642.

Andreoni, J. and L. Vesterlund, 2001. Which is the fair sex? Gender differences in altruism. Quarterly Journal of Economics 116, 293-312.

Baumeister, R.F., Bratslavsky, E., Muraven, M., and D.M. Tice, 1998. Ego Depletion: Is the active self a limited resource? Journal of Personality and Social Psychology 74, 1252-1265.

Becker, G. S., 1968. Crime and punishment: an economic approach. Journal of Political Economy 76, 169-217.

Benjamin, D.J., Brown, S.A., and J.M. Shapiro, 2012. Who is 'behavioral'? Cognitive ability and anomalous preferences. Journal of the European Economic Association 11, 1231-1255.

Birkeland, S., Cappelen, A.W., Sorensen, E., and B. Tungodden, forthcoming. An experimental study of prosocial motivation among criminals. Experimental Economics.

Cappalletti, D., Güth, W., and M. Ploner, 2011. Being of two minds: Ultimatum offers under cognitive constraints. Journal of Economic Psychology 32, 940-950.

Charness, G. and U. Gneezy, 2012. Strong evidence for gender differences in risk taking. Journal of Economic Behavior \& Organization 83, 50-58.

Chintrakarn, P. and D. Herzer, 2012. More inequality, more crime? A panel cointegration analysis for the United States. Economics Letters 116, 389-391.

Chmura, T., Engel, C., and M. Englerth, 2013. Selfishness as a potential cause of crime - a prison experiment. Preprints of the Max Planck Institute for Research on Collective Goods Bonn 2013/5.

Conte, A., Levati, M.V., and C. Nardi, 2013. The role of emotions on risk preferences: An experimental analysis. Jena Economic Research Paper 2013-046.

Cornelissen, G., Dewitte, S., and L. Warlop, 2011. Are social value orientations expressed automatically? Decision making in the Dictator Game. Personality and Social Psychology Bulletin 37, 1080-1090.

Croson, R. and U. Gneezy, 2009. Gender differences in preferences. Journal of Economic Literature 47, 1-27. 
DeBono, A., Shmueli, D., and M. Muraven, 2011. Rude and inappropriate: The role of selfcontrol in following social norms. Personality and Social Psychology Bulletin 37, 136-146.

DeHaan, W. and J. Vos, 2003. A crying shame: The over-rationalized conception of man in the rational choice perspective. Theoretical Criminology 7, 29-54.

DeWall, N.C., Baumeister, R.F., Gailliot, M.T., and J.K. Maner, 2008. Depletion makes the heart grow less helpful: Helping as a function of self-regulatory energy and genetic relatedness. Personality and Social Psychology Bulletin 34, 1653-1662.

Dreber, A. and M. Johannesson, 2008. Gender differences in deception. Economics Letters 99, 197-199.

Eckel, C.C. and P.J. Grossman, 2008. Differences in the economic decisions of men and women: Experimental evidence. In: Plott, C., and V. Smith (Eds.). Handbook of Experimental Economics Results, 509-519.

Engel, C., 2012. Low self-control as a source of crime. Preprints of the MPI for Research on Collective Goods 2012/4.

Erat, S. and U. Gneezy, 2012. White lies. Management Science 58, 723-733.

Evans, J., 2008. Dual-processing accounts of reasoning, judgment, and social cognition. Annual Review of Psychology 59, 255-278.

Fajnzylber, P., Lederman, D., and N. Loayza, 2002. What causes violent crime? European Economic Review 46, 1323-1357.

Falk, A. and U. Fischbacher, 2002. "Crime" in the lab - detecting social interaction. European Economic Review 46, 859-869.

Fehr, E. and K. Hoff, 2011. Introduction: tastes, castes and culture: the influence of society on preferences. Economic Journal 121, F396-F412.

Fischbacher, U., 2007. z-Tree: Zurich toolbox for ready-made economic experiments. Experimental Economics 10, 171-178.

Fleisher, B.M., 1966. The effect of income on delinquency. American Economic Review 56, 118-137.

Freeman, N. and M. Muraven, 2010. Self-control depletion leads to increased risk taking. Social Psychology and Personality Science 1, 175-181.

Fudenberg, D. and D.K. Levine, 2006. A dual-self model of impulse control. American Economic Review 96, 1449-1476.

Fudenberg, D. and D.K. Levine, 2011. Risk, delay, and convex self-control costs. American Economic Journal: Microeconomics 3, 34-68. 
Fudenberg, D. and D.K. Levine, 2012. Timing and self-control. Econometrica 80, 1-42.

Gino, F., Schweitzer, M.E., Mead, N.L., and D. Ariely, 2011. Unable to resist temptation: How self-control depletion promotes unethical behavior. Organizational Behavior and Human Decision Processes 115, 191-203.

Gneezy, U. and J. Potters, 1997. An experiment on risk-taking and evaluation periods. Quarterly Journal of Economics 112, 631-645.

Gottfredson, M.R. and T. Hirschi, 1990. A general theory of crime. Stanford, CA: Stanford University Press.

Guisi, L., Sapienza, P., and L. Zingales, 2013. Time varying risk aversion. NBER WP 19284.

Grasmick, H.G., Tittle, C.R., Bursik, R.J., and B.J. Arneklev, 1993. Testing the core empirical implications of the general theory of crime. Journal of Research in Crime and Delinquency 30, 5-29.

Greiner, B., 2003. An online recruitment system for economic experiments. In: Kremer, K., and V. Macho Eds., Forschung und wissenschaftliches Rechnen, GWDG Bericht 63, Göttingen: Ges. für Wiss. Datenverarbeitung, 79-93.

Hagger, M. S., Wood, C., Nikos, C. S., and L.D. Chatzisarantis, 2010. Ego depletion and the strength model of self-control: A meta-analysis. Psychological Bulletin 136, 495-525.

Haidt, J., 2001. The emotional dog and its rational tail: A social intuitionist approach to moral judgment. Psychological Review 108, 814-834.

Harbaugh, W.T., Mocan, N., and M.S. Visser, 2013. Theft and deterrence. Journal of Labor Research 34, 389-407.

Hauge, K., Brekke, K.A., Johansson, L.O., Stenmann-Johansson, O., and H. Svedsäter, 2009: Are social preferences skin deep? Dictators under cognitive load. Working Paper in Economics 371, University of Gothenburg.

Jacob, B., Lefgren, L., and E. Moretti, 2007. The dynamics of criminal behavior: evidence from weather shocks. Journal of Human Resources 42, 489-527.

Kahneman, D., 2003. A perspective on judgment and choice: Mapping bounded rationality. American Psychologist 58, 697-720.

Kahneman, D., 2011. Thinking, fast and slow. Macmillan.

Khadjavi, M., 2014. On the interaction of deterrence and emotions. Mimeo.

Lobel, J. and G. Loewenstein, 2005. Emote control: The substitution of symbol for substance in foreign policy and international law. Chicago Kent Law Review 80, 101-147. 
Moore, D.A. and G. Loewenstein, 2004. Self-interest, automaticity, and the psychology of conflict of interest. Social Justice Research 17, 189-202.

Muraven, M. (forthcoming). Ego-depletion: Theory and evidence. In R. M. Ryan (Ed.), Oxford handbook of motivation. Oxford: Oxford University Press

Muraven, M. and R.F. Baumeister, 2000. Self-regulation and depletion of limited resources: Does self-control resemble a muscle? Psychological Bulletin 126, 247-259.

Muraven, M., Pogarsky, G., and D. Shmueli, 2006. Self-control depletion and the general theory of crime. Journal of Quantitative Criminology 22, 263-277.

Muraven, M. and E. Slessareva, 2003. Mechanisms of self-control failure: Motivation and limited resources. Personality and Social Psychology Bulletin 29, 894-906.

Nguyen, Y. and C.N. Noussair, 2013. Risk aversion and emotions. CentER Discussion Paper 2013-041, Tilburg: Economics.

Pahlke, J., Strasser, S., and F.M. Vieider, 2012. Risk-taking for others under accountability. Economics Letters 114, 102-105.

Pratt, T.C. and F.T. Cullen, 2000. The empirical status of Gottfredson and Hirschi's General Theory of Crime: A meta-analysis. Criminology 38, 931-964.

Priks, M., 2010. Does frustration lead to unruly behavior? Evidence from the Swedish hooligan scene. Kyklos 63, 450-460.

Rachlin, H., 2002. Altruism and selfishness. The Behavioral and Brain Sciences 25, 239-250.

Rustichini, A., 2008. Dual or unitary system? Two alternative models of decision-making. Cognitive, Affective, and Behavioral Neuroscience 8, 355-362.

Schildberg-Hörisch, H. and C. Strassmair, 2012. An experimental test of the deterrence hypothesis. Journal of Law, Economics, and Organization 28, 447-459.

Schulz, J., Fischbacher, U., Thoeni, C., and V. Utikal, forthcoming. Affect and fairness: Dictator games under cognitive load. Journal of Economic Psychology.

Sutter, M., Kocher, M., and S. Strauss, 2003. Bargaining under time pressure in an experimental ultimatum game. Economics Letters 81, 341-347.

Unger, A. and D. Stahlberg, 2011. Ego-depletion and risk behavior: Too exhausted to take a risk. Social Psychology 42, 28-38.

Wikström, P.O.H. and K. Treiber, 2007. The role of self-control in crime causation: Beyond Gottfredson and Hirschi's General Theory of Crime. European Journal of Criminology 4, 237264. 
Xu, H., Bègue, L., and B.J. Bushman, 2012. Too fatigued to care: Ego depletion, guilt, and prosocial behavior. Journal of Experimental Social Psychology 48, 1183-1186. 


\section{Appendix A: Histograms}

In order to further document the gender-specific treatment effect, Figure 1 depicts the histograms for investments in the risky option in HSC and LSC for male and female subjects. It shows that the share of men who invest the maximum amount in the risky option (i.e., who behave in a risk-neutral or risk-seeking manner) increases substantially from about $15 \%$ in HSC to more than $40 \%$ in LSC. Figure 1 also illustrates the absence of a treatment effect regarding the behavior of female subjects.

Figure 1: Histograms of investment in risky option arranged by self-control and gender

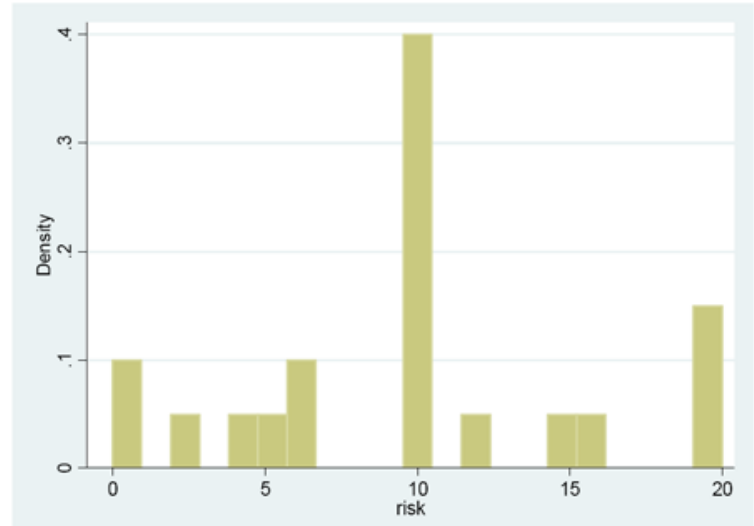

(a1) Male subjects in $\mathrm{HSC}(\mathrm{N}=21)$

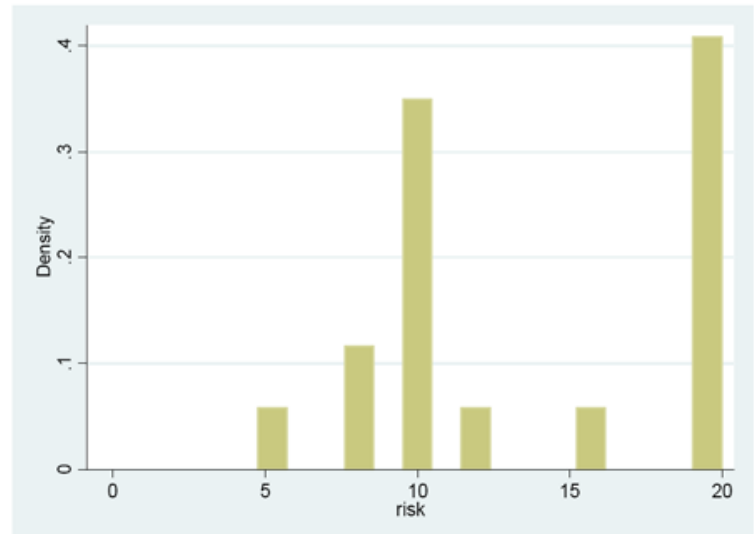

(a2) Male subjects in LSC ( $N=18)$

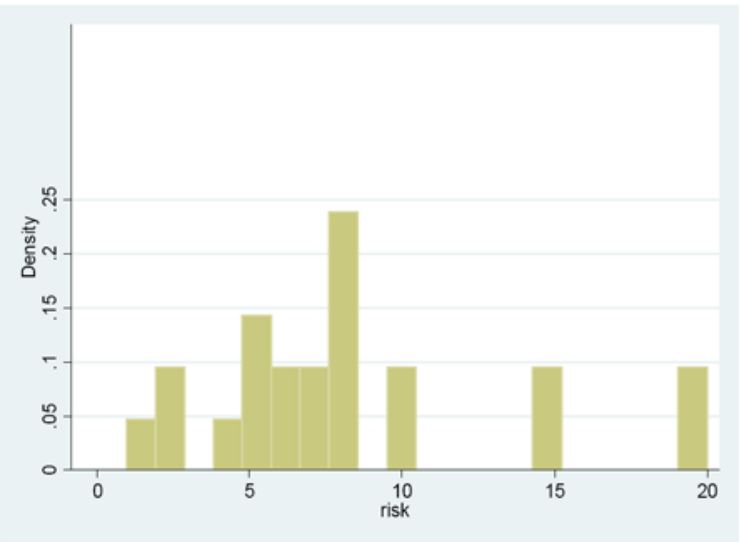

(b1) Female subjects in $\mathrm{HSC}(\mathrm{N}=22)$

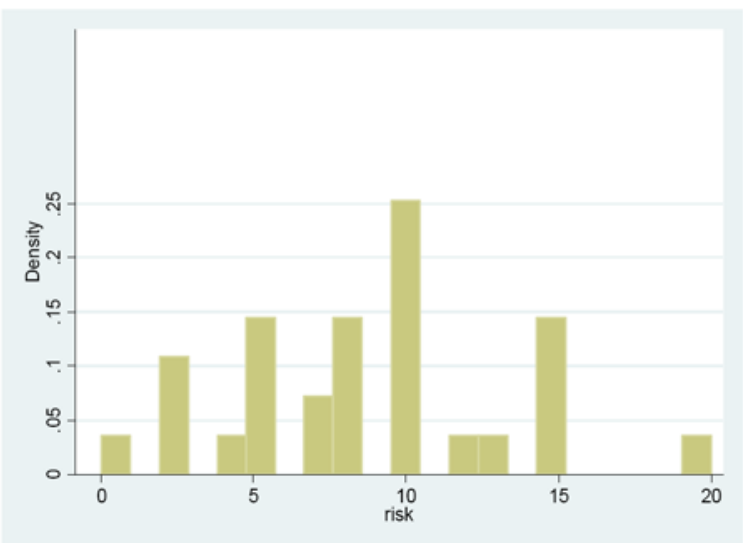

(b2) Female subjects in LSC ( $\mathrm{N}=29)$

Figure 2 presents gender-specific histograms of the taken amount in treatments HSC and LSC. They illustrate that social preferences of men are not affected by self-control, while women with high self-control tend to behave more antisocial. For example, close to $40 \%$ of women take the maximum amount of 20 points in HSC, while less than $15 \%$ do in LSC. 
Figure 2: Histograms of taken amount arranged by self-control and gender

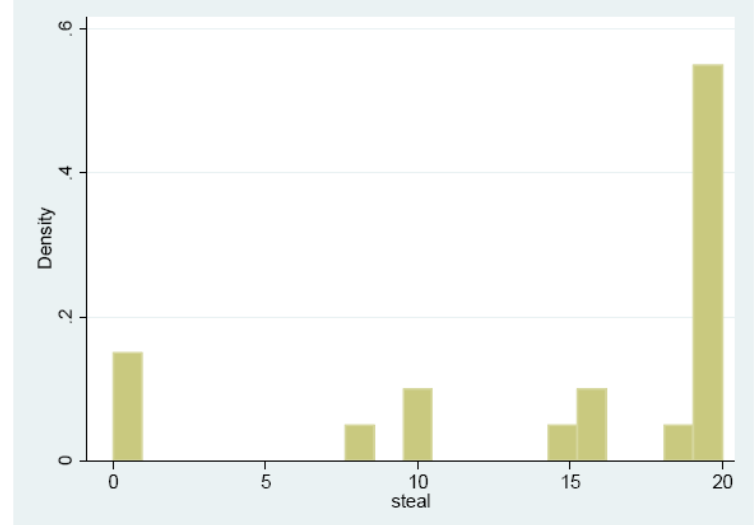

(a1) Male subjects in $\mathrm{HSC}(\mathrm{N}=21)$

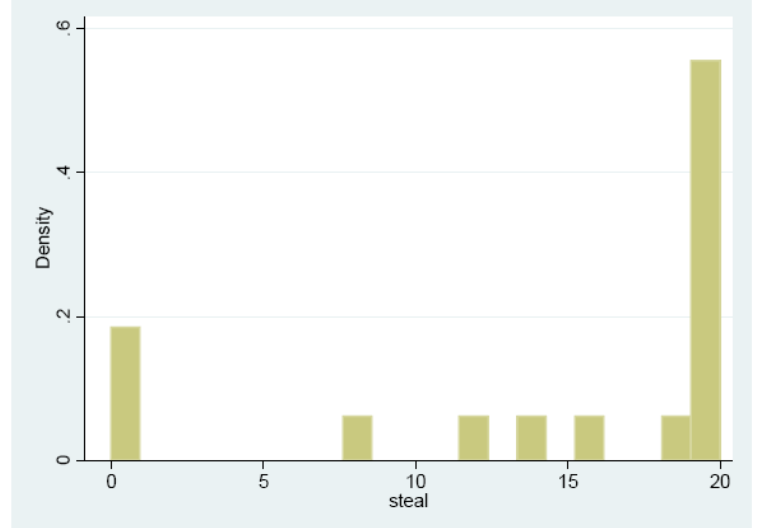

(a2) Male subjects in LSC ( $N=17)$

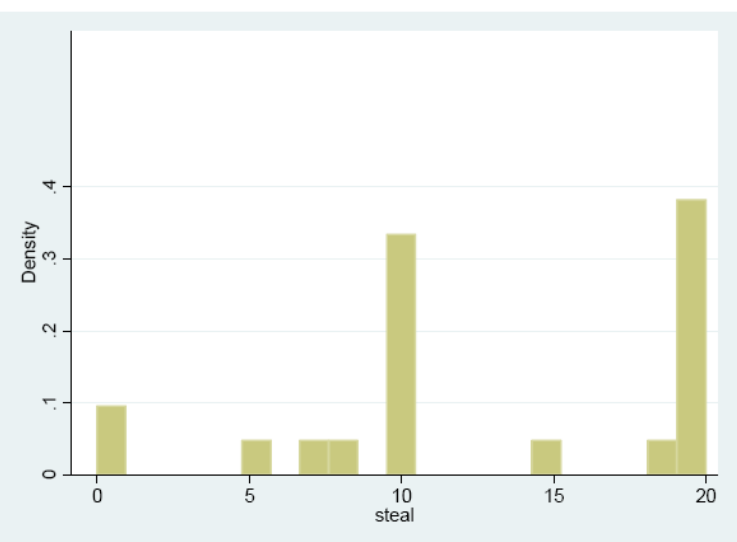

(b1) Female subjects in $\mathrm{HSC}(\mathrm{N}=22)$

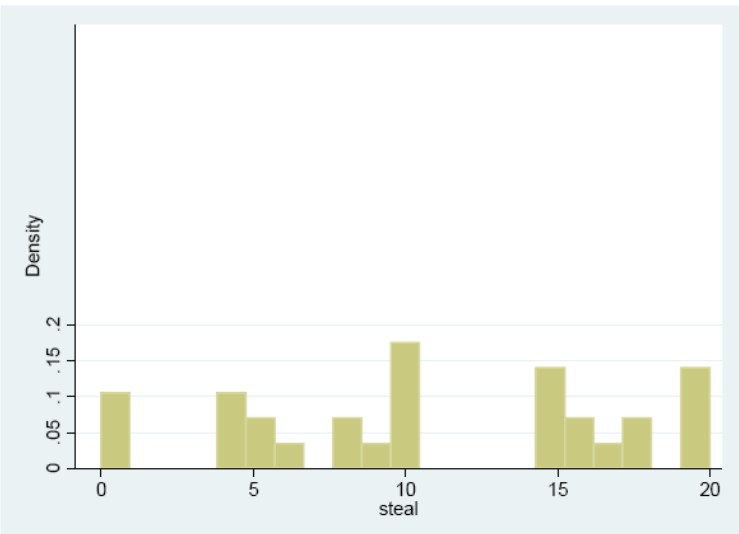

(b2) Female subjects in LSC (N=30) 


\title{
Appendix B: Translated version of the instructions for the LSC [HSC] treatment for risky
} investment first

\author{
General explanations
}

Welcome to this economic experiment.

In the following, we explain how you can earn money from your decisions in this experiment. Please read the instructions carefully. If you have any questions, please raise your hand and we will come to your seat.

During the whole experiment it is not allowed to talk to the other participants, to use cell phones, or to launch any programs on the computer. Disregarding any of these rules will lead to your exclusion from the experiment and from all payments.

During the experiment, your gains and losses are counted in points instead of in Euro. Your total income will be calculated in points first. At the end of the experiment, your total points will be converted into Euro: 1 point=25 Cents. At the end of the experiment, you will receive the income that results from your decision in cash.

In the following paragraphs we will describe the exact experimental procedure.

\section{The experiment}

First, we will describe your decision situation in general terms, using the variables $X$ and $Y$ that are explained below. We will assign numerical values to the variables $X$ and $Y$ during the course of the experiment and show them to you on the screen.

In this experiment, you will make a decision which influences only your payoff. You receive an endowment of $X$ points and decide how many of these $X$ points to invest in a risky asset. Your income in this experiment is determined by your investment level as follows:

If you invest 0 points, you will receive your endowment amounting to $X$ points as income.

If you invest more than 0 points, you will receive:

- with $50 \%$ probability, your endowment plus $Y$ times your investment level, that is, your income is $X+Y *$ Your investment. $Y$ is greater than 1 . 
- with $50 \%$ probability, your endowment minus your investment level, that is, your payoff is $X$-Your investment.

Your income as a function of your investment level is represented in the following figure:

\section{Your decision}
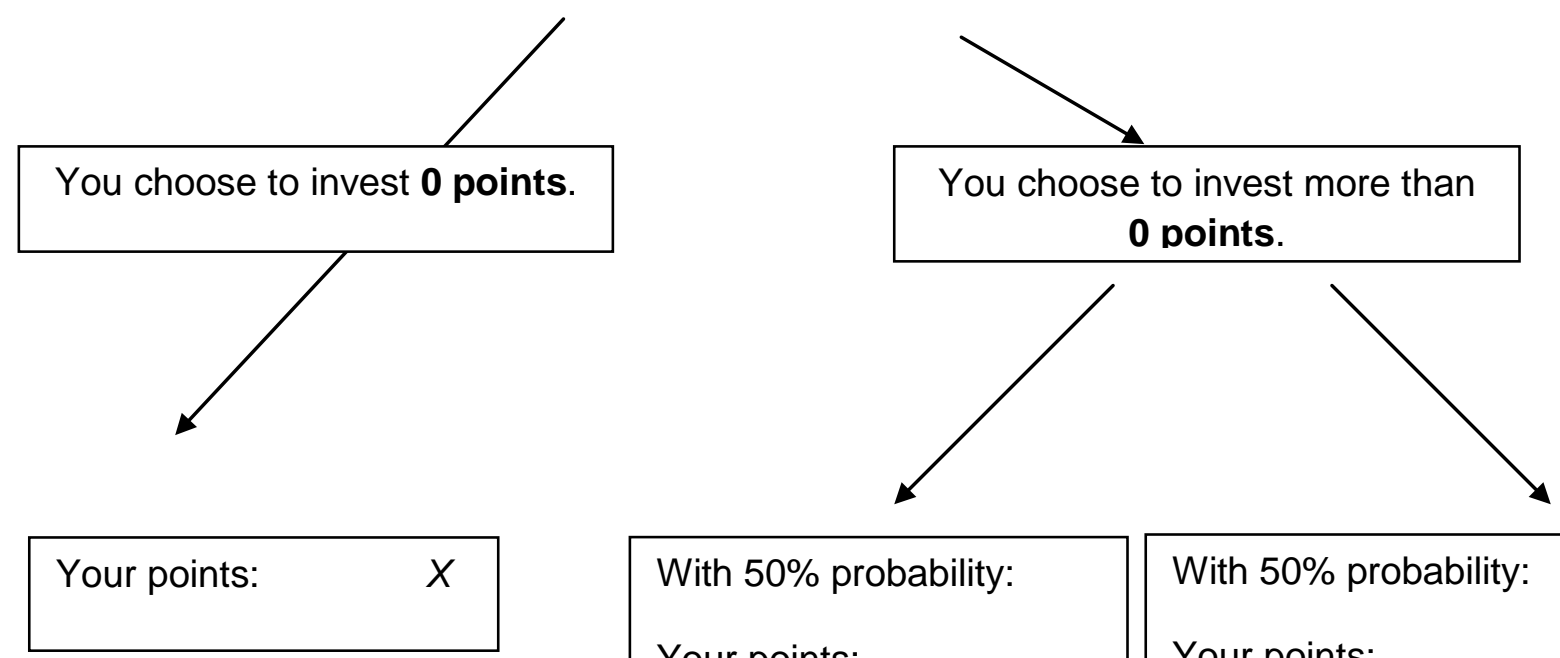

With 50\% probability:
Your points:
$X+Y *$ Your investment

With $50 \%$ probability:

Your points:

$X$ - Your investment

In order to determine how many points you would like to invest in the risky asset, specify the number of points in the according cell on screen and then press the OK-button. You will make this choice once. At the end of the experiment, you will be paid your income resulting from the investment decision in cash.

Before you make your decision, there are two tasks to be completed. It is very important for the experiment that you make an effort to complete the tasks diligently and correctly. For each task, you will be handed out a sheet of paper that you should work on. We will collect both sheets of paper at the end of the experiment. Moreover, you will receive private feedback onscreen about your performance in the two tasks at the end of the experiment.

\section{First task:}

We will hand out the first sheet of paper with text after all questions concerning the decision have been answered by the experimenters. Please cross out each instance of the letter " $\mathrm{e}$ " in the text. Start the task with working on the first paragraph and continue paragraph by paragraph. After you have finished a paragraph, specify the number of "e" you crossed out 
in the paragraph in the field below the paragraph. We will check later on whether you crossed out the number of " $\mathrm{e}$ " indicated.

You have 7 minutes to work on the task. Rather spend more time on few paragraphs and do them right instead of trying to do many paragraphs. The time remaining for the task is shown in the upper right corner of your screen. A new display will appear after the 7 minutes have passed. Please insert the number of counted " $\mathrm{e}$ " for each completed paragraph on the screen. Enter a zero for each paragraph not worked on or not completed.

\section{Second task:}

After you have finished the first task, we will hand out a second sheet of paper with text. You now have to cross out the letter " $\mathrm{e}$ " according to the following set of rules:

Generally you cross out the letter " $\mathrm{e}$ "; however, there are the following exceptions:

(a) there is a vowel in the text after the letter " $\mathrm{e}$ " or

(b) there is a vowel in the text two letters after the letter " $\mathrm{e}$ ", or

(c) there is a vowel in the text two letters before the letter " $\mathrm{e}$ ".

In counting letters, disregard full stops, commas, or spaces. You are asked to cross out the " $\mathrm{e}$ " if there is a vowel directly before the " $\mathrm{e}$ " (as, for instance, in the example "were engaged" (in German "etwa elf")). Vowels comprise: A, Ä, E, I, O, Ö, U, Ü.

The following representation summarizes the rules:

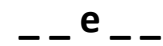

\section{4}

Cross out all " $\mathrm{e}$ " in principle. Exceptions: Do not cross out the " $\mathrm{e}$ " if there is a vowel on position 1,3 , or 4 .

[HSC Treatment: After you have finished the first task, we will hand out a second sheet of paper with text. Please again cross out each instance of the letter " $e$ " in the text. This is the same instruction as used for the first task.] 
Please start again with the first paragraph and continue paragraph by paragraph. Specify the number of " $\mathrm{e}$ " you crossed out in the paragraph in the field below it. We will check later on whether you crossed out the number of " $\mathrm{e}$ " indicated.

Again, you have 7 minutes to work on the task. Spend rather more time on few paragraphs and do them right instead of trying to do many paragraphs. The time remaining is shown in the upper right corner of the screen. A new display will appear after the 7 minutes have passed. Please insert the number of counted " $e$ " for each completed paragraph on the screen. Enter a zero for each paragraph not worked on or not completed.

Subsequent to the two tasks, you will make your previously described decision concerning the level of investment. At the end of the experiment, all participants will receive their income resulting from the investment decision in cash.

Please raise your hand in case you have any questions. One of the experimenters will come to you to answer it.

\section{Another experiment}

Next, you will make one further decision. This is your last decision in this experiment. Again, we will describe the decision situation in general terms. The numerical values of the variables $W$ and $Z$ that are introduced below will be shown onscreen during the course of the experiment.

There are two kinds of participants, A and B. You will participate as participant B. Your anonymity and your randomly assigned participant $A$ 's anonymity will be ensured during and after the experiment. Each pair consists of a real participant $A$ and a real participant $B$.

You as a participant $B$ receive an endowment amounting to $W$ points. Participant $A$ also receives an endowment of $\mathrm{W}$ points.

As participant B, you choose an integer transfer amount that you would like to take from participant A's endowment. Participant $A$ does not make a decision and cannot influence your payoff. For each point that you take from $A$, you receive $Z$ points. $Z$ is smaller than one. 
Your income is given by your endowment of $\mathrm{W}$ points plus $Z$ times your chosen transfer amount. Participant $A$ receives an income that equals his endowment of $W$ points minus the transfer amount determined by you.

Specifically: You determine how many points are transferred from participant A to you. Your income is ( $\mathrm{W}+\mathrm{Z}^{*}$ transfer amount) points. Participant $\mathrm{A}$ receives an income amounting to $(\mathrm{W}$ - transfer amount) points.

In order to determine how many points you would like to take from participant A, specify the number of points in the according cell on screen and press the OK-button.

At the end of the experiment, all participants $A$ and $B$ will receive their income resulting from the transfer decision in cash.

You will make this decision once. 